\title{
GLOBALIZAÇÃO E A EFETIVIDADE DO DIREITO HUMANO SOCIAL: PANORAMA HISTÓRICO E UMA ABORDAGEM SOBRE OS DILEMAS ATUAIS
}

\author{
GLOBALIZATION AND THE EFFECTIVENESS OF THE HUMAN SOCIAL RIGHT:
} HISTORICAL: HISTORICAL OVERVIEW AND AN APPROACH ON SOCIAL DILEMAS

\author{
André Pereira R. Tokarski ${ }^{1}$ \\ Ionas Deda Gonçalves ${ }^{2}$
}

\begin{abstract}
Resumo: O presente artigo traz em seu bojo uma análise entre o fenômeno da globalização e o direito humano social - num contexto da teoria do direito e direito positivado. Esse exame terá como ponto de partida uma abordagem dos direitos sociais no âmbito da Carta Constitucional de 1988 e a sua concreção eficacial. Em seguida, os direitos sociais como fenômeno da afirmação histórica dos direitos humanos. Depois, a constitucionalização dos direitos sociais em nível mundial. Em seguida, os direitos sociais e a crise econômica mundial e sua repercussão. Após, os direitos sociais e as guerras. Em seguida, os direitos sociais e a evolução dos direitos a partir da Declaração Universal dos Direitos Humanos de 1948. E, por fim, os direitos sociais e o fenômeno da globalização.
\end{abstract}

Palavras-chave: Direitos Humanos; Direitos Sociais; Globalização; Neoliberalismo.

Abstract: The present article brings to the fore an analysis between the phenomenon of globalization and the social human right - in a context of the theory of right and right positivado. This examination will have as its starting point an approach to social rights under the Charter of 1988 and its effective implementation. Then social rights as a phenomenon of the historical assertion of human rights. Then, the constitutionalization of social rights worldwide. Then social rights and the world economic crisis and its repercussion. After, social rights and wars. Then, social rights and the evolution of rights from the Universal Declaration of Human Rights of 1948. And, finally, social rights and the phenomenon of globalization.

Keywords: Human rights; Social rights; Globalization; Neoliberalism.

SUMÁRIO: INTRODUÇÃO - 1 OS DIREITOS SOCIAIS NO NASCEDOURO DA MODERNIDADE - 1.1 CIDADANIA, DIREITOS SOCIAIS E DEMOCRACIA - 1.2 A REVOLUÇÃO FRANCESA E A IDEIA DE DIREITOS UNIVERSAIS - 2 A GENERALIZAÇÃO DOS DIREITOS SOCIAIS - 2.1 A REVOLUÇÃO DE OUTUBRO

\footnotetext{
${ }^{1}$ Mestre em direitos político e econômico pela Universidade Presbiteriana Mackenzie e doutorando em direitos humanos pela Pontifícia Universidade Católica de São Paulo.

${ }^{2}$ Mestre e Doutor em direito pela Pontifícia Universidade Católica de São Paulo. Atualmente é Procurador Federal - Procuradoria-Geral Federal, professor assistente-mestre da Pontifícia Universidade Católica de São Paulo onde leciona nos cursos de graduação e pós-graduação em Direito.
} 
E A QUESTÃO SOCIAL - 2.2 OS DIREITOS SOCIAIS ENQUANTO DIREITOS HUMANOS: A DECLARAÇÃO UNIVERSAL DOS DIREITOS HUMANOS - 3 TEORIAS DA GLOBALIZAÇÃO E OS DIREITOS SOCIAIS NA CONTEMPORANEIDADE - 3.1 METÁFORAS DA GLOBALIZAÇÃO - 3.2 GLOBALIZAÇÃO E A SOCIEDADE REFLEXIVA - 3.3 A CONSTITUIÇÃO DE 1988: O ÚLTIMO SUSPIRO DO ESTADO DE BEM-ESTAR SOCIAL - 3.4 NEOLIBERALISMO E A CONSTITUIÇÃO DIRIGENTE INVERTIDA - 4. CONCLUSÃO - REFERÊNCIAS BIBLIOGRÁFICAS.

\section{INTRODUÇÃO}

O presente artigo trata da relação entre a Globalização e direito humano social, aqui compreendido como teoria do direito e direito positivado. O objetivo principal é apresentar, de forma sintética, um panorama histórico do aparecimento dos direitos sociais e analisar a sua efetividade diante da complexidade da atual sociedade global.

Trataremos também do caso brasileiro, especialmente da condição dos direitos sociais no âmbito da Constituição de 1988 e dos impactos da chamada "constituição dirigente invertida" para a sua efetividade.

Os argumentos desenvolvidos nesse artigo percorrem, resumidamente, o seguinte itinerário: a) os direitos humanos no geral e os direitos sociais, particularmente, são um fenômeno histórico cuja gênese remete às lutas sociais decorrentes do desenvolvimento do capitalismo e de suas contradições, aceleradas pelo que o historiador britânico Eric J. Hobsbawm chamou de dupla revolução: a Revolução Industrial inglesa contemporânea e a Revolução Francesa de 1789; b) os direitos sociais adquirem um novo impulso e passam a figurar em diversas Constituições ocidentais no início do século XX. A Revolução Bolchevique na Rússia, de 1917, alçou a questão social ao centro da agenda política global; c) As condições políticas depois de 1945 reclamavam a concessão de novos e abrangentes direitos sociais. O saldo de duas guerras mundiais e uma grande crise econômica (1929) apontava para a necessidade dos Estados assumirem responsabilidades efetivas na promoção e garantia de condições dignas de vida da população. É nesse contexto que surge a Declaração Universal dos Direitos Humanos, de 10 de dezembro de 1948, para diversos autores o documento jurídico mais importante da história contemporânea; d) a compreensão da 
sociedade global como uma totalidade complexa, contraditória e em movimento; e) uma breve análise sobre o caso brasileiro, particularmente sobre a efetividade dos direitos sociais inscritos na Constituição de 1988, diante da hegemonia do pensamento neoliberal e da “constituição dirigente invertida".

Para esse estudo utilizaremos tanto referências da teoria crítica do direito, que compreende o fenômeno jurídico não apenas no âmbito das normas estatais, como também o referencial normativista/positivista, como meio adequado para travar o debate sobre a efetividade dos direitos sociais.

\section{OS DIREITOS SOCIAIS NO NASCEDOURO DA MODERNIDADE}

\subsection{CIDADANIA, DIREITOS SOCIAIS E DEMOCRACIA}

Data do final do século XVIII o acontecimento de dois episódios que marcaram em definitivo a crise do antigo regime europeu e levaram o mundo a ingressar na modernidade: a Revolução Industrial Inglesa e a Revolução Francesa de 1789.

Num contexto mais amplo, insere-se também no rol desses acontecimentos a Independência dos Estados Unidos, em 1776.

Do ponto de vista político, especialmente a Declaração de Independência dos Estados Unidos e a Revolução Francesa promovem uma ruptura no princípio da legitimidade vigente até então: deixa de ser baseado nos deveres dos súditos e passa a estruturá-lo a partir dos direitos do cidadão. Seria o nascedouro da ideia de cidadania (PINSKY, 2013, p. 10).

Essas transformações e seus efeitos econômicos e sociais, políticos e culturais constituem o que hoje chamamos de Primeira Revolução Industrial e marcam o surgimento do Estado moderno.

No começo da era industrial as cidades eram ambientes extremamente insalubres, desprovidas de serviços como saneamento, transporte, higiene, saúde e educação regular. A inexistência de leis que regulamentassem as relações de trabalho durante o inicio da era industrial, e por boa parte do século XIX, levou os trabalhadores a enfrentarem condições de trabalho extremamente duras: longas jornadas, tarefas exaustivas, salários insuficientes para a subsistência de suas famílias, etc. Com essas condições não restava aos trabalhadores outra saída, senão lançar-se em lutas por melhorias nas condições de trabalho (SINGER, 2013). 
Entretanto, o terreno para a conquista de reivindicações de melhorias nas relações de trabalho era amplamente desfavorável, como retrata Paul Singer:

Em 1799, o Parlamento britânico (em resposta a uma petição de mestres denunciando uma combinação) aprovou uma lei proibindo as combinações de trabalhadores em geral - ou seja, em qualquer atividade. Os culpados primários, que se combinassem para ganhar aumento de salário ou que solicitassem a alguém que deixasse o trabalho ou que objetassem em trabalhar com outras pessoas, podiam ser condenados a três meses de cadeia ou dois meses de trabalho forçado (SINGER, 2013, pag. 197).

Se as greves (ou combinações, como chamadas à época) poderiam resultar em prisão ou condenações a trabalho forçado, a via judicial, como meio de obter decisões favoráveis ao amparo dos trabalhadores, também não se revelara um caminho aberto a tais demandas. A lei impunha multa de dez libras a quem contribuísse para a defesa de algum condenado (por litígios envolvendo as relações de trabalho). Apelações das sentenças estavam sujeitas ao pagamento de garantias de vinte libras, um valor exorbitante, fora do alcance do trabalhador comum (SINGER, 2013, p. 197).

As dificuldades dos trabalhadores não se restringiam às penosas relações de trabalho. Também se refletiam no âmbito dos direitos civis e políticos. A consolidação do Estado moderno traz consigo o pressuposto jurídico da igualdade formal entre todos os indivíduos, uma conquista civilizatória - mesmo que ainda no plano da legalidade e não da materialidade.

Ainda assim, no que diz respeito aos direitos políticos, não foi automática a implementação do sufrágio universal, por exemplo. Importantes pensadores liberais à época, como o inglês Edmund Burke e o francês Emmanuel Joseph Sieyès - autor de um dos mais célebres manifestos da revolução francesa, chegaram a classificar os trabalhadores braçais ou assalariados como máquinas de trabalho" ou instrumentum vocale (instrumento que fala), ou ainda "instrumentos bípedes". Tais visões serviam para justificar o voto censitário e negar, na prática, os direitos políticos aos não proprietários (LOSURDO, 2013, p. 32).

Os anos inicias da modernidade apontavam para um cenário de não reconhecimento, na prática, dos direitos políticos, civis e sociais dos trabalhadores. A sociedade moderna, e mais adiante a contemporânea, adquiriu um grau de complexidade tamanho que a divisão clássica dos direitos do cidadão em individuais, políticos e sociais não parece dar conta dessa realidade. Para PINSKY (2013, p. 9), exercer a cidadania plena é ter direitos civis, políticos e sociais: "os direitos civis e políticos não asseguram a democracia sem os direitos sociais, aqueles que garantem a participação do indivíduo na riqueza coletiva: o direito à educação, ao 
trabalho, ao salário justo, à saúde, a uma velhice tranquila". Os direitos civis e políticos não seriam o suficiente para assegurar a democracia sem os direitos sociais.

\subsection{A REVOLUÇÃO FRANCESA E A IDEIA DE DIREITOS UNIVERSAIS}

Compreendemos a Revolução Francesa (1789) como a fundadora dos direitos civis e como o passo definitivo para o inicio da superação do antigo regime. Há uma mudança paradigmática com o fim da relação entre súditos e a nobreza real e a partir da ideia universalista de que todos são iguais perante a lei.

O artigo primeiro da Declaração estabelece que "os homens nascem e permanecem livres e iguais em direitos", tais direitos são naturais e imprescritíveis e cabe a toda e qualquer associação política sua defesa e conservação. Esses direitos consistem na liberdade, no direito à propriedade, na segurança e na resistência à opressão (ODALIA, 2013, p. 167).

A Revolução Francesa tem seu início datado da reunião dos Estados Gerais, convocados pelo rei Luís XVI, em 1789. Porém, a própria convocação foi desencadeada por incessantes levantes camponeses, que começaram em 1774, quando Luis XVI foi coroado.

O contexto em que ocorre o processo revolucionário na França é marcado por inúmeros motins e revoltas. A fome se alastrava por todo o país e a principal medida tomada pela nobreza era intensificar a repressão, o que servia como combustível para ampliar o ímpeto revolucionário dos que já não tinham quase nada a perder.

De 1775 a 1777 explodiram inúmeros motins. Eram motins da fome, até então contidos unicamente pela força. A colheita de 1774 fora má; escasseava o pão. Então explodiu o motim de 1775. Em Dijon o povo apoderou-se das casas dos açambarcadores; destruiu-lhes os móveis e quebrou-lhes os moinhos. Foi nesta ocasião que o governador da cidade disse ao povo essa frase funesta que mais tarde foi repetida tantas vezes durante a Revolução: "a grama já está crescida, ide para os campos pastá-la". (SINGER, 2013, P. 207).

A Declaração dos direitos do homem e do cidadão, da França de 1789, inaugura uma nova era de direitos. Os direitos naturais e imprescindíveis do homem passam a quatro: a liberdade, a propriedade, a segurança, e a resistência à opressão (TRINDADE, 2011, p. 36).

Certamente, um dos grandes legados da Revolução Francesa foi alçar a um patamar de não retorno a fundamentação política e jurídica do conceito universal de homem, ideia fundamental para o desenvolvimento dos direitos humanos. Mesmo que figurasse ainda no 
plano da idealidade e da legalidade, tal noção é uma ruptura paradigmática e essencial para a busca da plena dignidade humana.

A Revolução Francesa recoloca também o debate sobre os direitos naturais e, em relação a esse ponto, acompanhamos a visão de José Damião de Lima Trindade, para quem o direito é essencialmente uma relação histórica:

Contemporaneamente, vai se impondo a concepção de que o direito, longe de ser "natural", é uma relação social e histórica, cambiante, manifestação dos interesses em conflito entre os homens em cada sociedade, expressão, antes de mais nada, dos interesses daqueles que detêm poder para formulá-lo e para exigir o seu cumprimento. (TRINDADE, 2011, P. 36).

Em que pese o liberalismo europeu e norte-americano terem contribuído decisivamente para a compreensão do conceito universal de homem, fundamento essencial para os direitos humanos, parte relevante dos liberais há época reclamava outros atributos ou qualidades para que o individuou fosse plenamente "humanizado":

Malgrado tudo o que já fora escrito sobre os direitos naturais dos homens e sua igualdade essencial, esses e tantos outros discursos da época tiveram a apreciável virtude, hoje incomum nos pensadores liberais, de explicitar com clareza no que realmente acreditavam os liberais: no limite, levavam em conta apenas seus interesses, conveniências e preconceitos de classe - a ponto de um fato não-natural, não intrínseco às pessoas, como a propriedade e/ou renda, ser tomado como critério jurídico para a concessão de direitos (TRINDADE, 2011, p. 52).

Para TRINDADE (2011), essa vertente do pensamento liberal relativiza a plenitude e integralidade da condição humana a depender de certos atributos ou qualidades de gênero, origem racial e, especialmente, se se trata da classe de proprietários ou não. Esse é o fundamento que justificou, sem qualquer constrangimento, a restrição parcial dos direitos humanos ou até mesmo a sua interdição completa.

\section{A GENERALIZAÇÃO DOS DIREITOS SOCIAIS}

\subsection{A REVOLUÇÃO DE OUTUBRO E A QUESTÃO SOCIAL}

Tanto quanto a Revolução Francesa de 1789, a Revolução Russa de 1917 é merecedora da atenção e estudo por parte dos interessados em buscar a origem e o desenvolvimento histórico dos direitos sociais. Tamanha é a influência da Revolução Russa 
que o célebre historiador britânico Eric Hobsbawm batizou de "breve século XX" o período da história marcado pela sua gênese e derrocada (iniciado com a Primeira Guerra Mundial, em 1914 e encerrado com a dissolução da então União Soviética, em 1991) (FERNANDES, 2017, p. 7).

Para melhor compreender o contexto da Revolução Russa de 1917, também chamada de Revolução de Outubro, ou Revolução Bolchevique, recuaremos alguns passos para uma brevíssima abordagem das lutas sociais e das ideias em confronto que marcaram a Europa e boa parte do mundo na segunda metade do século XIX.

A Revolução de Outubro é descendente direta das ideias de Karl Marx e Friederich Engels, autores, dentre outras obras, do Manifesto do Partido Comunista, publicado pela primeira vez em fevereiro de 1848. O Manifesto expõe as linhas gerais das ideias que influenciaram o movimento operário e dos trabalhadores durante a segunda metade do século XIX e adentraram no século XX. Faz uma denúncia contundente das péssimas condições de vida dos trabalhadores, assenta a contradição entre as classes sociais e a desigualdade premente num regime de exploração, onde o trabalho é social e a apropriação destes frutos é privada, e apresenta um programa com medidas que vão desde a abolição da propriedade privada dos meios de produção, até a defesa de reivindicações imediatíssimas dos trabalhadores, como a redução da jornada de trabalho (que chegava a alcançar $14 \mathrm{~h}$ a $16 \mathrm{~h}$ diárias), o fim do trabalho infantil, a oferta de ensino público para todos, entre outros. Abaixo destacamos um trecho que trata do preço do trabalho assalariado:

O preço médio do trabalhado assalariado é o mínimo do salário, é a soma dos meios de vida que são necessários para manter vivo o operário como operário. Aquilo, portanto, de que o operário se apropria pela sua atividade chega apenas para gerar de novo a sua vida nua. De modo nenhum queremos abolir esta apropriação pessoal dos produtos de trabalho para a nova geração da vida imediata — uma apropriação que não deixa nenhum provento liquido capaz de conferir poder sobre trabalho alheio. Queremos suprimir apenas o caráter miserável desta apropriação, em que o operário só vive para multiplicar o capital, só vive na medida em que o exige o interesse da classe dominante (MARX; ENGELS, 1997, p. 18).

O Manifesto do Partido Comunista não figurou sozinho nesse cenário, influenciou correntes políticas sociais-democratas, sindicatos e movimentos de trabalhadores. Um exemplo é programa de Erfurt, aprovado em 1891 no Congresso do Partido SocialDemocrático dos Trabalhadores Alemães. Entre as reivindicações, constavam pautas relacionadas aos direitos políticos e sociais: 
sufrágio universal; eleições diretas em âmbito nacional, estadual e municipal; participação popular nas decisões de política externa; democratização do aparelho judicial (com eleição dos magistrados); ensino básico gratuito e obrigatório para todos; liberdade de expressão e de organização; abolição da pena de morte; imposto incidindo sobre as rendas dos ricos; leis de proteção aos trabalhadores; assistência médica gratuita para a população, cobrindo inclusive gastos com os partos e funerais; e revogação de todos os dispositivos legais que resultassem em discriminação contra as mulheres (KONDER, 2013, p. 185-186).

Para KONDER (2013), o programa de Erfurt reunia pontos de vista marxistas e lassalleanos $^{3}$ e buscava refletir aspirações das massas de trabalhadores alemães. Foram tempos de mobilizações e greves que chegavam a reunir centenas de milhares de trabalhadores. Invariavelmente, estas reivindicações combinavam a promoção e o reconhecimento de direitos civis, políticos e sociais aos trabalhadores. A pressão exercida pelos socialistas, em nome da opinião pública, resultou também na conquista do sufrágio universal masculino, que os liberais recalcitravam em admitir (e, salvo exceções, retardaram o voto feminino até o século XX).

A pressão exercida pelas massas operárias foi decisiva para a consagração dos direitos sociais em várias Constituições no início do século $\mathrm{XX}$, nomeadamente a Constituição do México de 1917 e a Constituição de Weimar de 1919.

Mas o impulso decisivo para a generalização dos direitos sociais ocorreu após a Revolução Russa de outubro 1917. Para FERNANDES (2017, p. 8), "a revolução soviética colocou a questão social (baseada da promoção de amplos direitos sociais e na redução acelerada da desigualdade) na agenda política mundial, de forma abrangente e profunda".

De acordo com FERNANDES (2017), esse processo se desenvolveu em duas frentes: em realizações internas e em influência externa, de forma indireta. No âmbito das realizações internas, ocorreram transformações nas estruturas sociais herdadas do antigo Império Russo promovendo uma profunda e acelerada redução das desigualdades, combinada com uma ampla promoção de direitos sociais e políticos, como a alfabetização de milhões de analfabetos, politicas de habitação arrojadas, a democratização da saúde, a redução da jornada de trabalho, a legalização do divórcio, o direito ao voto feminino, entre outros.

Do ponto de vista da influência externa, ocorreu a afirmação indireta da questão social em função da "ameaça" que o bloco socialista representava para as elites das potências capitalistas. Essa influência ajudou a modelar e estruturar o Estado de bem-estar e a

\footnotetext{
${ }^{3}$ Ferdinand Lassalle foi contemporaneo de Karl Marx. É tido como um dos precursores da social-democracia alemã.
} 
generalizar os direitos sociais na Europa e também em países capitalistas dependentes, como o Brasil.

A União Soviética também influenciou sobremaneira a formação do atual sistema internacional de nações. Sua atuação diplomática, política, econômica e militar apoiou processos de descolonização após a Segunda Guerra Mundial e ajudou a estruturar (pelo menos do ponto de vista formal) o princípio da autodeterminação dos povos (FERNADES, 2017).

Tal ocorrência tem impacto relevante no âmbito do estudo dos direitos humanos, tendo em vista que a constitucionalização de tais direitos foi decisivamente influenciada pela Declaração Universal dos Direitos Humanos, construída e viabilizada na esfera das instituições que compõe este sistema internacional de nações.

\subsection{OS DIREITOS SOCIAIS ENQUANTO DIREITOS HUMANOS: A DECLARAÇÃO UNIVERSAL DOS DIREITOS HUMANOS}

As condições políticas depois de 1945 eram favoráveis à concessão de novos e abrangentes direitos sociais. $\mathrm{O}$ saldo de duas guerras mundiais e uma grande crise econômica (1929) apontava para a necessidade de os Estados assumirem responsabilidades efetivas na promoção e garantia de condições dignas de vida da população. A primeira metade do século XX submeteu a classe trabalhadora, sobretudo na Europa, a sofrimentos extremos. Acumulouse um anseio por mudanças e a pressão do campo socialista influenciou o grande avanço do estado de bem-estar nos trinta "anos dourados" que se seguiram à restauração da paz (SINGER, 2013, p. 248).

No final da Segunda Guerra Mundial, em 1944, mesmo com os conflitos em andamento, a Organização Internacional do Trabalho (OIT) realizou uma importante conferência. Dela resultou a "Declaração da Filadélfia", mais tarde incorporada à própria Constituição da OIT. Para Singer (2013, p. 248), a Declaração da Filadélfia "eleva os direitos sociais ao nível dos demais direitos humanos, quando afirma que todos os seres humanos gozam de direitos de viver com segurança econômica e oportunidades iguais".

A Declaração Universal dos Direitos Humanos incorporou em seu texto demandas referentes aos direitos sociais. Para GREGORI (2011, p. 158) a Declaração "promove o reconhecimento universal dos diretos humanos e das liberdades fundamentais, e delineia tanto 
os direitos civis e políticos (arts. III a XXI), como os direitos sociais, econômicos e culturais (arts. XXII a XXVIII)".

Apesar de não possuir caráter vinculante, os Estados signatários da Declaração Universal dos Direitos Humanos assumiram o compromisso de fazer valer os direitos ali afirmados. Em muitos casos, como o brasileiro, pontos fundamentais da Declaração foram incorporados à Constituição. Para produzir efeitos jurídicos vinculantes aos direitos previstos na Declaração a ONU, em 1966, elaborou dois pactos internacionais: o de direitos econômicos, sociais e culturais e o de direitos civis e políticos (GREGORI, 2011).

O Brasil aderiu ao Pacto Internacional dos Direitos Econômicos, Sociais e Culturais (PIDESC), aprovado na Assembleia Geral das Nações Unidas em 16 de dezembro de 1966. Entretanto, o Pacto só passou a viger no Brasil a partir da publicação do Decreto $\mathrm{N}^{\mathrm{o}} 591$ de 6 de julho de 1992.

\section{TEORIAS DA GLOBALIZAÇÃO E OS DIREITOS SOCIAIS NA CONTEMPORANEIDADE}

\subsection{METÁFORAS DA GLOBALIZAÇÃO}

Partimos da compreensão de que a sociedade global constitui-se, desde o inicio, como uma totalidade problemática, complexa e contraditória, aberta e em movimento. Já no seu nascedouro o capitalismo estaria propenso a se tornar um sistema global, desde o século XVI, Holanda, Inglaterra, França, Alemanha, Estados Unidos, Japão e outras nações, transitaram como centro dinâmico desse sistema (IANNI, 2002, p. 171).

A partir de sua acumulação originária, desde o mercantilismo, atravessando o colonialismo, o imperialismo, o multinacionalismo, o transnacionalismo e o globalismo, o desenvolvimento do capitalismo influenciou sobremaneira os desenhos e limites das fronteiras que formam o mapa mundial.

Para IANNI (2002, p. 171), “ainda que tenha sido sucessiva e simultaneamente nacional, regional e internacional, juntamente com sua vocação colonialista e imperialista, o capitalismo se torna no século $\mathrm{XX}$ um modo de produção não só internacional, mas propriamente global."

No âmbito dos direitos humanos, o processo de expansão dos domínios do capitalismo é marcado por graves violações de direitos, extermínio de povos originários, 
escravização, coação física, subjugação, entre outras transgressões. O mercantilismo, o colonialismo, e o imperialismo, períodos históricos distintos da expansão capitalista, tem em comum a exploração e subjugação de outros povos e nações.

Tanto na fase colonial (séc. XVI a XVIII), como no período do imperialismo (séc. XIX), o mecanismo que opera e justifica as invasões militares, a subjugação e o domínio político e econômico de uma nação contra outros povos ou nações é o mesmo: a ideia da existência de povos civilizados e bárbaros, ou de raças humanas superiores e inferiores. Negando ou confessando, os países que lideraram a expansão capitalista ao longo dos últimos séculos partem desse pressuposto. Assim nos ensina João Quartim de Moraes na apresentação do livro O pecado original do século XX, de Domenico Losurdo:

O constante cuidado em apoiar-se em fatos públicos e notórios e em declarações dos próprios responsáveis pelo cortejo de abominações que acompanharam a conquista do planeta pelo Ocidente imperialista torna a argumentação de Losurdo especialmente convincente. Assim, ele lembra que Hitler costumava ressaltar a afinidade profunda entre seus métodos de espoliação e extermínio com os do Far West estadunidense. Os nazistas inverteram o ponto cardeal, subjugando e massacrando os indígenas do seu Far East (a Europa Oriental), por eles classificados de sub-homens (Untermenschen). O rei Leopoldo II da Bélgica, durante o Congresso de Berlim (1884-85), em que as potências da Europa partilharam alegremente a África, declarou-se animado pelo propósito de "levar a civilização para a única parte do globo que ela ainda não atingiu". Entre 1890 e 1911, a obra civilizatória dos belgas reduziu a população do Congo de cerca de 40 milhões a 8 milhões de habitantes. Meio século depois, Mussolini adotou a mesma ideia: após a guerra de extermínio que moveu contra os indígenas da Líbia (que teimavam em resistir à colonização italiana implantada em 1912), declarou em dezembro de 1934 que a Etiópia, "ultima fatia da África que não tinha patrões europeus", não passava de um "pseudo Estado bárbaro e negreiro". A invasão fascista levou aos etíopes alguns primores da civilização europeia: gases letais, bombardeios aniquiladores, campos de concentração, etc (LOSURDO, 2013, p. 10).

FERNANDES (2017, p. 17) caracteriza o termo imperialismo como "a ação de um Estado para estender a sua soberania ou influência sobre outros povos, nações e territórios". Essa expansão dos domínios de um Estado para além de seus limites territoriais préestabelecidos era movida essencialmente pelo desejo de poderosos interesses financeiros de conquistar novos mercados.

Em última instância, o ímpeto pela maximização dos lucros e pela acumulação de capital, se traduziu em relações de dominação política e apropriação econômica em âmbito global, atravessou territórios e fronteiras, nações e nacionalidades. (IANNI, 2002, P. 40). 
Para IANNI (2002), “o modo capitalista de produção pode ser visto como um todo complexo, desigual, contraditório e dinâmico, uma totalidade aberta ou propriamente histórica. Está sempre em movimento, no sentido de que se transforma e expande, entra em crise e retorna a sua expansão, de maneira errática mas progressiva, com frequência inexorável".

\subsection{GLOBALIZAÇÃO E A SOCIEDADE REFLEXIVA}

Trazendo uma abordagem original para o fenômeno da globalização, Ulrich Beck (2010) formula um conceito autêntico a respeito e traz à tona o debate sobre a sociedade reflexiva. Para BECK (2010, p. 23), na modernidade tardia, "a produção social da riqueza é acompanhada sistematicamente pela produção social de riscos".

De acordo com BECK, encontramo-nos, pelo menos desde os anos setenta, no início de uma marcante transição: "ainda não vivemos numa sociedade de risco, mas tampouco somente em meio a conflitos distributivos das sociedades de escassez. Na medida em que essa transição se consuma, chega-se então, com efeito, a uma transformação social que se distancia das categorias e trajetórias habituais de pensamento e ação" (BECK, 2010, P. 25).

A distribuição e os conflitos distributivos em torno da riqueza socialmente produzida ocuparão o primeiro plano enquanto em países e sociedades o pensamento e a ação das pessoas forem dominados pela evidência da carência material, pela "ditadura da escassez". (BECK, 2010, P. 24).

Como é possível que as ameaças e riscos sistematicamente coproduzidos no processo tardio de modernização sejam evitados, minimizados, dramatizados, canalizados e, quando vindos à luz sob a forma de "efeitos colaterais latentes", isolados e redistribuídos de modo tal que não comprometam o processo de modernização e nem as fronteiras do que é (ecológica, medicinal, psicológica ou socialmente) “aceitável”? (BECK, 2010, P. 24).

Ao mesmo tempo, importa indagar em que medida as promessas do desenvolvimento científico e tecnológico, capazes de elevar os índices de produtividade industrial a patamares jamais imaginados, estão efetivamente contribuindo para a redução das desigualdades sociais e para a erradicação da miséria.

Considerava-se que o progresso científico e o progresso moral avançassem lado a lado. Hoje, sobre o progresso triunfante da ciência e da técnica, não temos dúvidas. Sobre o concomitante progresso moral, ao contrário, seria melhor suspender qualquer juízo. E contudo, nunca como nos últimos anos, 
em especial depois da Segunda Guerra Mundial, o tema dos direitos do homem, de cuja afirmação Kant deduzira o motivo para acreditar no progresso moral da humanidade, foi novamente reproposto à atenção da opinião pública mundial (BOBBIO, 2000, p. 476).

\subsection{A CONSTITUIÇÃO DE 1988: O ÚLTIMO SUSPIRO DO ESTADO DE BEM- ESTAR SOCIAL}

A Constituição da República Federativa do Brasil de 1988 (CF/1988) incorporou um amplo arcabouço de objetivos políticos, sociais e econômicos a serem alcançados, além de constitucionalizar um extenso rol de direitos sociais. Ela se situa nos marcos de uma Constituição transformadora, ou seja, que propõe objetivos e metas a serem alcançados ao longo de determinado período.

A CF/1988 traz em seu artigo $3^{\circ}$ a incorporação de um programa de transformações econômicas e sociais a partir de uma série de princípios e objetivos fundamentais de política social e econômica a serem realizados pelo Estado brasileiro (BERCOVICI, 2011). A análise do Título VII, Da Ordem Econômica e Financeira, em conjunto com os arts. $1^{\circ}, 3^{\circ}$ e $4^{\circ}$, constituem as bases de um projeto nacional de desenvolvimento.

A interpretação dos artigos $3^{\circ}, 170$ e 219, dentre outros, da CF/1988, revela que é tarefa do Estado brasileiro atuar para a superação do subdesenvolvimento. Para tal, enseja-se a reestruturação e o fortalecimento do Estado sob uma perspectiva democrática e emancipatória (OCTAVIANI, 2014).

Nessa perspectiva, segundo OCTAVIANI (2014), é possível identificar na CF/1988 um nítido projeto emancipatório, que inclui expressamente no texto constitucional as tarefas que o povo brasileiro entende como absolutamente necessárias para a superação do subdesenvolvimento e conclusão da construção da Nação.

Essa tarefa está, como sabemos, constitucionalmente determinada, não apenas no artigo 3o da Constituição de 1988, que estabelece que o desenvolvimento nacional é objetivo da República, nem apenas no artigo 170, I da Constituição, que visa reafirmar a soberania econômica nacional. Há, na Constituição, ainda, a previsão expressa da política de internalização dos centros de decisão econômica do país, no seu artigo 219, que determina que o mercado interno integra o patrimônio nacional e que deve ser incentivado de modo a viabilizar o desenvolvimento cultural $\mathrm{e}$ socioeconômico, o bem-estar da população e a autonomia tecnológica do País (GRAU, 2000, p. 77). 
A CF/1988incorporou em seu texto as bases de um projeto nacional de desenvolvimento. O capítulo II da CF/1988 é, todo ele, reservado aos direitos sociais. O artigo $7^{\circ}$ enumera nada menos que 34 direitos dos trabalhadores urbanos e rurais, merecendo destaque os seguintes: relação de emprego protegida contra despedida arbitrária, segurodesemprego, salário mínimo, $13^{\circ}$ salário, jornada de trabalho de oito horas por dia, férias anuais remuneradas, licença remunerada de 120 dias para gestantes, entre outros.

A julgar pela abrangência dos dispositivos constitucionais que tratam dos direitos sociais, dir-se-ia que o Brasil é um dos mais completos estados de bem estar social do planeta. Entretanto, é sabido que parcela destes direitos sociais ainda figuram no plano programático, sendo limitada a sua efetividade.

A CF/1988 é uma Constituição econômica e dirigente. Transformou fins sociais e econômicos em jurídicos. Dito de outra maneira, a diretriz constitucional, em sua forma jurídica, é contornada de objetivos e finalidades no ordenamento econômico e social. Essa compreensão deve ser vinculada à interpretação de todo o texto constitucional (BERCOVICI, 2011).

\subsection{O NEOLIBERALISMO E A CONSTITUIÇÃO DIRIGENTE INVERTIDA}

No inicio dos anos 1970 o modelo econômico do pós-guerra sofre uma grave crise que leva todo o mundo capitalista avançado a uma longa e profunda recessão. Depois de mais de 20 anos de crescimento ininterrupto, pela primeira vez combinam-se baixas taxas de crescimento com altas taxas de inflação. É a ruína do consenso keynesiano e a abertura de espaço para as ideias neoliberais. Alguns dos principais defensores destas ideias apressaramse para apontar os motivos da crise:

As raízes da crise, afirmavam Hayek e seus companheiros, estavam localizadas no poder excessivo e nefasto dos sindicatos e, de maneira mais geral, do movimento operário, que havia corroído as bases de acumulação capitalista com suas pressões reivindicativas sobre os salários e com sua pressão parasitária para que o Estado aumentasse cada vez mais os gastos sociais (ANDERSON, 1995, p.10).

Para enfrentar a crise, os defensores do neoliberalismo prescreveram um robusto ajuste nos gastos sociais e nas intervenções do Estado na economia. A estabilidade monetária deveria ser a meta suprema de qualquer governo. Para isso seria necessário uma "disciplina orçamentária, com a contenção dos gastos de bem-estar social, e a restauração da taxa 
'natural' de desemprego, ou seja, a criação de um exército de reserva de trabalho para quebrar os sindicatos" (ANDERSON, 1995, p.11).

Para BERCOVICI (2006), o orçamento público continua sendo um instrumento essencial, mas não serve mais, preponderantemente, para, por meio de direitos sociais e serviços públicos, assegurar a reprodução da força de trabalho, passando também a ser disputado com o objetivo de garantir a remuneração do próprio capital. As mudanças do processo de acumulação de capital, notadamente a 'financeirização' do capitalismo, como ocorre a partir da década de 1970, e as políticas neoliberais de ajuste fiscal, representariam riscos à efetividade dos direitos sociais.

A constituição dirigente das políticas públicas e dos direitos sociais passou a ser entendida como prejudicial aos interesses do país, causadora última das crises econômicas, do déficit público e da "ingovernabilidade".

"A constituição dirigente invertida, isto é, a constituição dirigente das políticas neoliberais de ajuste fiscal é vista como algo positivo para a credibilidade e a confiança do país junto ao sistema financeiro internacional. Esta, a constituição dirigente invertida, é a verdadeira constituição dirigente, que vincula toda a política do Estado brasileiro à tutela estatal da renda financeira do capital, à garantia da acumulação de riqueza privada (BERCOVICI, MASSONETO, 2006, p. 71)".

A Constituição de 1988 foi promulgada numa época em que as políticas neoliberais já estavam em pleno curso na América do Norte e Europa e penetrando na América Latina. Provavelmente, a Constituição Federal de 1988 seja uma das últimas de seu gênero que contenha, de modo reiterado, a afirmação de um projeto transformador que vise alcançar um patamar de bem-estar social e de redução das desigualdades.

\section{CONCLUSÃO}

Nos marcos dos 70 anos da Declaração Universal dos Direito Humanos e dos 30 anos da promulgação da Constituição Federal de 1988, os debates sobre a efetividade dos direitos sociais face a um processo acelerado de globalização econômica, política e social, guardam atualidade e relevância.

Os direitos sociais não são reconhecidos no rol de direitos naturais. Nem mesmo figuraram na constitucionalização das declarações de direitos das primeiras constituições liberais dos séculos XVIII e XIX. Somente a partir do início do século XX é que os diretos 
sociais são incorporados em boa parte das constituições. Esse processo se generaliza após a Segunda Guerra Mundial e tem na Declaração Universal dos Direitos Humanos, em 1948, um ponto alto para a sua universalização.

Os direitos sociais não se referem apenas à satisfação de cada individuo isoladamente, mas também ao chamado interesse da coletividade. $\mathrm{O}$ reconhecimento e a efetividade dos direitos sociais requerem a atuação direta do Estado, o que denomina-se direitos de prestação, caso em que o Estado necessariamente precisa intervir para a concretização das providências almejadas. Ocorre que tal atuação ultrapassa a esfera subjetiva da garantia jurídica e requer a existência de instituições adequadas para o seu cumprimento e a disponibilidade de meios materiais para tal.

A própria discussão sobre a liberdade enquanto um direito fundamental ganha novo contorno. Para Bobbio (2000), sem a satisfação de algumas exigências fundamentais da vida material, a liberdade seria vazia, estéril. Os direitos sociais deveriam colocar o individuo em condições de ter o poder para fazer aquilo que é livre para fazer.

Tal compreensão nos leva, inevitavelmente, ao debate sobre como concretizar o Estado de bem estar social diante da escassez de recursos públicos disponíveis. O processo de globalização trouxe consigo a retórica do controle do déficit público, discurso que ganha força e atinge quase um grau de consenso a partir do final do anos 1980. As políticas de ajuste fiscal implementadas desde então se mostraram ineficazes na contenção do endividamento público, apesar dos recortes aplicados reiteradamente nos investimentos sociais. O déficit público antes aplicado com vistas ao pleno emprego, hoje é o que garante a remuneração para o capital.

A efetividade dos direitos humanos, no geral, e do direito humano social, particularmente, já deu passos largos na direção de sua concretização. É inconteste a relevância da constitucionalização destes direitos no ordenamento jurídico nacional, entretanto, ainda resta muito a ser feito no sentido de garantir objetivamente a plena realização dos direitos sociais.

\section{REFERÊNCIAS BIBLIOGRÁFICAS}

ANDERSON, Perry. Balanço do neoliberalismo. In: SADER, Emir; GENTILI, Pablo (Org.). Pós-neoliberalismo: As políticas sociais e o estado democrático. Rio de Janeiro: Paz e Terra, 1995. p. 9-30. 
BECK, Ulrich. Sociedade de risco: rumo a uma outra modernidade. Tradução de Sebastião Nascimento. 2a ed., 2a reimpressão, São Paulo: Editora 34, 2010.

BERCOVICI, Gilberto. Direito econômico do petróleo e dos recursos minerais. São Paulo: Quartier Latin, 2011.

Teoria do Estado e teoria da Constituição na periferia do capitalismo: breves indagações críticas. In: COUTINHO, Jacinto Nelson de Miranda; Coutinho; LIMA, Martonio Montalverne Barreto (Org.). Diálogos constitucionais: direito, neoliberalismo e desenvolvimento em países periféricos. Rio de Janeiro: Renovar, 2004. p. 263-290.

; MASSONETO, Luis Fernando. A constituição dirigente invertida: a blindagem da Constituição Financeira e a agonia da Constituição Económica. Boletim de Ciências Econômicas XLIX. - Coimbra: Faculdade de Direito da Universidade de Coimbra, 2006. Disponível em: http://hdl.handle.net/10316.2/24845. Acesso em: 2018, fev. 2018.

BOBBIO, Norberto. Teoria geral da política: a filosofia política e as lições dos clássicos. Rio de Janeiro: Elsevier, 2000. Organizado por Michelangelo Bovero; Tradução de Daniela Beccaccia Versiani.

BRASIL. Constituição da República Federativa do Brasil, promulgada em 5 de outubro de 1988. Disponível em: http://www.planalto.gov.br/ccivil_03/constituicao/constituicao.htm. Acesso em: 16 abr. 2018.

Decreto n. 591, de 06 de jul. de 1992. Atos Internacionais. Pacto Internacional sobre Direitos Econômicos, Sociais e Culturais. Promulgação. Disponível em: http://www.planalto.gov.br/ccivil_03/decreto/19901994/d0591.htm?TSPD_101_R0=b0a7724db27622363d7bed8840ed455bkl30000000000000 000ebf378bdffff00000000000000000000000000005ad86751005bd5c2a0. Acesso em: 05 mar. 2018.

Senado Federal. Direitos Humanos. 4a ed. - Brasília: Coordenação de Edições Técnicas, 2013.

FERNANDES, Luis. A revolução bipolar: a gênese da derrocada do socialismo soviético. Rio de Janeiro: Ed. Puc-rio; Anita Garibaldi (São Paulo), 2017. 260 p.

GRAU, Eros Roberto. A ordem econômica na Constituição de 1988: interpretação e crítica. 5. ed. São Paulo: Malheiros, 2000

GREGORI, Maria Stella. O impacto do Programa Nacional de Direitos Humanos 3 para o direito do consumidor. Revista de Direito do Consumidor, v. 73, p. 149-166, 2010.

HOBSBAWM, Eric. A era das revoluções, 1789 - 1848. São Paulo: Companhia da Letras, 2012.

IANNI, Octavio. Teorias da globalização. $10^{\mathrm{a}}$ ed. Rio de Janeiro: Civilização Brasileira, 2002. 
LOSURDO, Domenico. O pecado original do século XX. São Paulo: Anita Garibaldi; Fundação Maurício Grabois, 2013. Tradução: Diego Silveira Coelho e Ana Maria Chairini.

OCTAVIANI, Alessandro. Estudos, pareceres e votos de direito econômico. São Paulo: Singular, 2014.

ODÁLIA, Nilo. Revolução francesa: a liberdade como meta coletiva. In: PINSKY, Jaime e PINSKY, Carla Bannenezi (orgs.). História da cidadania. 6a ed.- São Paulo: Contexto, 2013. p. $177-190$.

SINGER, Paul. Direitos Sociais: a cidadania para todos. In: PINSKY, Jaime e PINSKY, Carla Bannenezi (orgs.). História da cidadania. 6a ed. São Paulo: Contexto, 2013. p. 212 297.

TRINDADE, José Damião de Lima. Os direitos humanos na perspectiva de Marx e Engels: emancipação política e emancipação humana. São Paulo: Editora Alfa-Omega, 2011. 